\title{
SPE 131609
}

\author{
Static and Dynamic Estimates of $\mathrm{CO}_{2}$ Storage Capacity in Two Saline Formations in \\ the UK \\ Min Jin, SPE, Gillian Pickup, SPE, Eric Mackay, SPE, Adrian Todd, SPE, Heriot-Watt University, Alison Monaghan, \\ British Geological Survey, and Mark Naylor, University of Edinburgh
}

Copyright 2010, Society of Petroleum Engineers

This paper was prepared for presentation at the SPE EUROPEC/EAGE Annual Conference and Exhibition held in Barcelona, Spain, 14-17 June 2010.

This paper was selected for presentation by an SPE program committee following review of information contained in an abstract submitted by the author(s). Contents of the paper have not been reviewed by the Society of Petroleum Engineers and are subject to correction by the author(s). The material does not necessarily reflect any position of the Society of Petroleum Engineers, its officers, or members. Electronic reproduction, distribution, or storage of any part of this paper without the written consent of the Society of Petroleum Engineers is prohibited. Permission to reproduce in print is restricted to an abstract of not more than 300 words; illustrations may not be copied. The abstract must contain conspicuous acknowledgment of SPE copyright.

\begin{abstract}
Estimation of $\mathrm{CO}_{2}$ storage capacity is a key step in the appraisal of $\mathrm{CO}_{2}$ storage sites. Different calculation methods may lead to widely diverging values. The compressibility method is a commonly used static method for estimating storage capacity of saline aquifers: it is simple, easy to use and requires a minimum of input data. Alternatively, a numerical reservoir simulation provides a dynamic method which includes Darcy flow calculations. More input data are required for dynamic simulation, and it is more computationally intensive, but it takes into account migration pathways and dissolution effects, so is generally more accurate and more useful. For example, the $\mathrm{CO}_{2}$ migration plume may be used to identify appropriate monitoring techniques, and the analysis of trapping mechanism for a certain site will help to optimize well location and injection plan.

Two hypothetical saline aquifer storage sites in the UK, one in Lincolnshire and the other in the Firth of Forth, were analysed. The Lincolnshire site has a comparatively simple geology, while the Forth site has a more complex geology. For each site both static and dynamic capacity calculations were performed. In the static method, $\mathrm{CO}_{2}$ was injected till the average pressure reached a critical value. In the migration monitoring case, $\mathrm{CO}_{2}$ was injected for 15 years was followed by a closure period lasting thousands of years. The fraction of dissolved $\mathrm{CO}_{2}$ and the fraction immobilised by pore scale trapping were calculated.

The results of both geological systems show that the migration of $\mathrm{CO}_{2}$ is strongly influenced by the local heterogeneity. The calculated storage efficiency for the Lincolnshire site varied between $0.34 \%$ and $0.61 \%$ of the total pore volume, depending on whether the system boundaries were considered open or closed. Simulation of the deeper, more complex Forth geological system gave storage capacities as high as $1.05 \%$.

This work was part of the CASSEM ( $\mathrm{CO}_{2}$ Aquifer Storage Site Evaluation and Monitoring) integrated study to derive methodologies for assessment of $\mathrm{CO}_{2}$ storage in saline formations. Although, static estimates are useful for initial assessment when less data is available, we demonstrate the value of performing dynamic storage calculations, and the opportunities to identify mechanisms for optimising the storage capacity.
\end{abstract}

\section{Keywords: $\mathrm{CO}_{2}$, Storage Capacity, Saline Aquifer}

\section{Introduction}

Carbon Capture and Storage (CCS) is considered to be an important means of reducing greenhouse gas emissions. $\mathrm{CO}_{2}$ may be stored in depleted oil and gas fields, deep saline aquifers or unmineable coal seams. Of these options, deep saline aquifers have the greatest storage potential both world-wide (IPCC, 2005) and in the UK (SCCS, 2009). However, there is much uncertainty in the size and structure of aquifers compared to hydrocarbon reservoirs and estimation of $\mathrm{CO}_{2}$ storage capacity is therefore a key step in the appraisal of $\mathrm{CO}_{2}$ storage sites. This procedure is, however, complex (Bachu et al., 2007a; van der Meer and Egberts, 2008) and the results of estimations at regional or global level are widely scattered (Bachu et al., 2007a) due to different assumptions and lack of data. One of the most important assumptions is the boundary condition, i.e. whether the aquifer is closed (finite) or open (the formation outcrops, or is so large that the pressure does not increase at the boundaries), because this affects pressure build-up.

The selection of static or dynamic methods depends on the scale of the assessment and the type, quantity and quality of data available. In general, the methods used for calculating subsurface volume for $\mathrm{CO}_{2}$ storage can be divided into two categories: static and dynamic (Frailey, 2009). In the static method, the parameters are independent of time, i.e. the properties of the fluid and the rock are constant. On the contrary, the parameters in a dynamic model are time dependent. The most commonly used static 
methods are the volumetric method (Chadwich et al., 2006; DOE, 2006; Holloway, 1996), and the compressibility method (van der Meer and Egberts, 2008; Zhou et al., 2008). Examples of dynamic methods are decline curve analysis (Frailey, 2009), material balance (Mathias et al., 2009a; Zhou et al., 2008), and reservoir simulation.

\section{Static methods for $\mathrm{CO}_{2}$ storage capacity assessment Volumetric method}

The volumetric method assumes that the volume of $\mathrm{CO}_{2}$ which can be stored in an aquifer may be calculated from the product of the bulk volume, the average porosity and a storage efficiency factor, $E$, to account for the fact that only part of the accessible volume is available for $\mathrm{CO}_{2}$ storage.

$$
V_{\mathrm{CO}_{2}}=E \times V_{\text {pore }}=E \times \phi \times V_{\text {bulk }}
$$

$E$ is therefore the ratio of the pore volume containing $\mathrm{CO}_{2}$ to the total pore volume. (Note that a full list of symbols used is given in the Nomenclature at the end of the paper.) Details of this method are given in many publications (Bachu et al., 2007a; DOE, 2008). Assessments may be made either at the regional or basin scale for screening purposes, or at the local scale for planning storage in a particular aquifer. The efficiency $E$ is a combination of many factors and is often given in the form of the product of a number of coefficients (DOE, 2008). These coefficients incorporate the cumulative effects of trap heterogeneity, gravity and sweep efficiency, etc, and need to be determined through numerical simulations (Bachu et al., 2007a; Bachu et al., 2007b; Chadwick et al., 2006; Kaldi and Gibson-Poole, 2008). In addition, residual and dissolution trapping should also be taken into account. However, these effects are time and path dependent (Bachu et al., 2007a). The assessment of these trapping coefficients at the local and site scale by reservoir simulation can help the volumetric assessment at the basin scale.

Note that in the volumetric method, a value for the storage efficiency, $E$, has to be assumed. In all other methods discussed below, $E$ can be calculated. The volumetric method is not considered further here.

\section{Compressibility method}

The basic assumption of the compressibility method is that the boundaries of the aquifer model are closed, and therefore the pore space occupied by the injected fluid depends on the compressibility of the rock and existing fluids (Obdam, 2000; van der Meer and Egberts, 2008).

$$
E=V_{\mathrm{CO}_{2}} / V_{\text {pore }}=\left(c_{p}+c_{w}\right) \Delta P_{\max }
$$

where $c$ is compressibility, $\Delta P_{\max }$ is the maximum allowable pressure increase and the subscripts $p$ and $w$ refer to the pore space and the water respectively. This method provides a conservative estimate as no water can flow across the boundaries to reduce the pressure and because $\mathrm{CO}_{2}$ dissolution is neglected. Note that once the right side of Equation (2) has been evaluated, $V_{C O 2}$ may be calculated (assuming $V_{\text {pore }}$ is known). Then, for a given injection rate, the maximum time for injection may be computed. Using the estimated average $\mathrm{CO}_{2}$ density, the capacity in terms of Mt may also be calculated.

\section{Dynamic methods for $\mathrm{CO}_{2}$ storage capacity assessment}

When properties are considered to change with pressure and temperature, a dynamic model is required. Full dynamic modelling, which is discussed below, is time-consuming. However, a number of simple analytical and semi-analytical methods have been developed as screening tools for the basin- and field-scale assessment. The simplest of these is the material balance method, which is a special case of the compressibility method with pore pressure varying with time, so that the properties of fluids also vary with time (Frailey and Finley, 2009). More detailed methods have been developed by a number of people (Mathias et al., 2009b; Nordbotten and Celia, 2005; Nordbotten and Celia, 2006; Zhou et al., 2008). Of these, we consider the method of Zhou et al. (2008) in more detail.

\section{Semi-Closed Aquifer}

In many aquifers, the seals (top and bottom) are not completely impermeable, but have low permeabilities which allow brine to migrate from the aquifer as the pressure builds up. Zhou et al. (2008) have developed a method to describe such a system. In this model, it is assumed that the aquifer is homogeneous and that the seals above and below are of equal thickness, $H_{s}$ (although the method can be easily extended to seals of different thickness). The injected $\mathrm{CO}_{2}$ remains within the aquifer (excluded from the sealing layers by capillary pressure), but water may migrate uniformly through the seals. It is also assumed that the pressure builds up uniformly in the aquifer. The storage efficiency $E$ is then given by the following equation (adapted from Zhou et al. (2008), Eq. 2 , at time $\left.\mathrm{t}=\mathrm{t}_{\max }, \Delta \mathrm{P}(\mathrm{t})=\Delta \mathrm{P}_{\max }\right)$ : 


$$
E=\left(c_{p}+c_{w}\right) \Delta P_{\max }+\frac{1}{2}\left(c_{p}+c_{w}\right) \frac{V_{s}}{V_{\text {pore }}} \Delta P_{\max }+\frac{2 A k_{s}}{\mu_{w} H_{s} V_{\text {pore }}} \int_{0}^{t_{\max }} \Delta P(t) d t,
$$

where $A$ is horizontal area, $H$ is thickness, $k$ is permeability, $\mu$ is viscosity, $\Delta P$ is pressure build-up, $t$ is time, and the subscript $s$ is for seal. As the pressure builds up, the contributions to the brine displacement in the formation and the seals, and the leakage from the system can be computed. Because the pressure build-up affects the leakage rate at the cap rock, iteration is required to solve Equation 3. A major disadvantage with the method is that the pressure build-up is independent of formation permeability. Mathias et al. (Mathias et al., 2009a) recently considered pressure-dependent fluid and formation properties in their semi-analytical method for injectivity calculation.

\section{Reservoir Simulation}

Reservoir simulation is the most sophisticated method of estimating $\mathrm{CO}_{2}$ storage capacity, because it allows us to model the following physical processes, which are important for $\mathrm{CO}_{2}$ storage:

- $\quad$ build up of pressure in the near well region and throughout the aquifer;

- migration of $\mathrm{CO}_{2}$ by advection and buoyancy;

- dissolution in brine;

- residual trapping of $\mathrm{CO}_{2}$ in brine (due to hysteresis in relative permeability).

In addition, simulation allows us to take account of the effect of heterogeneities in an aquifer (e.g. Ukaegbu et al., 2009), as well as actual aquifer geometry, well location, injection interval, variable injection scenarios, non isothermal effects, permeability impairment due to brine evaporation and salt precipitation, etc. More data on the structure of the rock formations and the petrophysical properties (permeability and porosity) are required to build a geological model, in addition to fluid property data. Simulations of $\mathrm{CO}_{2}$ storage are obviously time-consuming if a full compositional simulation is run over long periods (e.g. 20 years of injection followed by a further 10,000 years after injection has ceased). Although full simulation is not suitable for making basin-scale estimates of $\mathrm{CO}_{2}$ storage due to the excessive runs times and lack of accurate data, simulations are very useful for assessing storage capacity at the local- and site-scale. ECLIPSE ${ }^{\mathrm{TM}} \mathrm{E} 300$ with the CO2STORE module (Schlumberger, 2010) was used in this study.

\section{Pressure Build-up, and the relation between maximum injection pressure and average field pressure}

When using the compressibility or the semi-closed methods, we need to decide on the maximum allowable increase in the average pressure in the aquifer. One of the basic assumptions of the two methods is that pressure is the same anywhere in the aquifer, so that the average field pressure equals the bottom hole pressure. In reality, however, the build-up of pressure near a well is likely to be critical, and this can only be judged using reservoir simulation. The maximum injection pressure can be decided by using rock mechanical information for a formation, while the maximum increase of average pressure depends on the total volume injected and the compressibility of the formation. The relation between injection pressure and average pressure is site-dependent and is the key link between a simple static method (e.g. compressibility method) and a dynamic method (e.g. numerical simulation).

From geomechanical point of view, the maximum pressure can be estimated with the following equation from Eaton (1969):

$$
\frac{P_{f}}{Z}=\frac{P_{p}}{Z}+\left(\frac{\sigma_{v}}{Z}-\frac{P_{p}}{Z}\right)\left(\frac{v}{1-v}\right)
$$

where $P / Z$ is a pressure gradient, $\sigma_{v} / Z$ is the vertical stress gradient, $v$ is Poisson's ratio, and the suffices $f$ and $p$ are for fracture and pore. If we take typical values for these gradients of $P_{p} / Z=0.01 \mathrm{MPa} / \mathrm{m}$, and $\sigma_{v} / Z=0.02268 \mathrm{MPa} / \mathrm{m}=2.268 P_{p} / Z$, and $v=0.3$, then the ratio of the fracture pressure gradient to the pore pressure gradient is 1.54 .

Some researchers estimate the maximum pressure as the fracture pressure. For example, Zhou et al. (2008) give a value of 1.3 1.8 times the initial pore pressure depending on the formation depth, cap rock type and strength. An investigation carried out by Van der Meer for leak off pressures (LOP) from drilled wells offshore of the Netherlands showed that the LOP changes from 1.35 times of hydrostatic pressure at $1000 \mathrm{~m}$ to 2.4 times at $5000 \mathrm{~m}$ (Obdam, 2000). If the trend is assumed to be linear between these depths, the ratio at the depths of interest in this study $(1100 \mathrm{~m}-2000 \mathrm{~m})$ will be between about 1.4 and 1.6 . If the boundaries of a storage site are closed, the capacity will be mainly decided by the maximum increase in the average pressure, if using the compressibility method.

Obviously, the maximum pressure increase due to the injection will occur at a well, so the maximum average pressure increase in the aquifer should be less than this. Van der Meer and Yavuz (2009) recently (van der Meer and Yavuz, 2009) used a 1 MPaincrease in average pressure in an onshore site assessment using the compressibility method. This resulted in a storage coefficient of $0.1 \%$ using typical compressibility values. Using the compressibility method, and assuming that the maximum pressure was the fracture pressure, a study of potential storage sites for $\mathrm{CO}_{2}$ from Scottish power stations (SCCS, 2009) found a range of storage 
efficiencies between $0.1 \%$ and $0.5 \%$, depending on the depth and compressibility of the formation. However, there is obviously a risk in allowing the average pressure to reach the fracture pressure.

In order to assess the effect of pressure variation within an aquifer, we assume that the aquifer is a homogeneous cylinder with a single well in the centre, and apply the radial flow equations, as in well testing. We split Equation (2) into two parts:

$$
E=c_{t} \times\left(\bar{P}-P_{i}\right)=c_{t} \times\left(P_{f}-P_{i}\right)-c_{t} \times\left(P_{f}-\bar{P}\right)
$$

where $P_{f}$ is the fracture pressure, $\bar{P}$ is the average pressure throughout the aquifer after injection, $P_{i}$ is the initial pressure and $c_{t}$ is the total compressibility: $c_{t}=c_{p}+c_{w}$. Consider the case where the pressure is in semi-steady-state, i.e. the pressure disturbance due to injection has reached the boundaries. The solution for the difference between the well pressure and the average pressure in the aquifer, for single-phase flow, is derived in many reservoir engineering textbooks (e.g. Dake, 1978) and is given by:

$$
P_{w}-\bar{P}=\frac{q \mu}{2 \pi k h} \ln \left(\frac{r_{e}}{r_{w}}-\frac{3}{4}\right)=\frac{q \mu}{2 \pi k h} \ln \left(\frac{0.47 r_{e}}{r_{w}}\right)
$$

where $P_{w}$ is the well pressure, $q$ is the injection rate, $\mu$ is viscosity, $k$ is permeability, $h$ is formation thickness, $r_{w}$ is the well radius and $r_{e}$ is the external radius. Taking account of the fact that $\mathrm{CO}_{2}$ is displacing brine, we get (van der Meer and Egberts, 2008):

$$
P_{w}-\bar{P}=\frac{q}{2 \pi k h}\left[\mu_{\mathrm{CO} 2} \ln \left(\frac{r_{\mathrm{CO} 2}}{r_{w}}\right)+\mu_{\text {brine }} \ln \left(\frac{0.47 r_{e}}{r_{\mathrm{CO} 2}}\right)\right]
$$

where $r_{\mathrm{CO} 2}$ is the radius of the $\mathrm{CO}_{2}$ front (assuming piston-like displacement). Since the compressibility and viscosity of $\mathrm{CO}_{2}$ changes with pressure, this equation must be solved iteratively. However a rough estimate of the difference between the well pressure and the average pressure may be made assuming constant viscosity. The viscosity of brine from Table 4 is 0.001 Pas. We assumed that the viscosity of $\mathrm{CO}_{2}$ is 0.1 times the viscosity of brine $=0.0001$ Pas, that the well radius, $\mathrm{r}_{\mathrm{w}}=0.15 \mathrm{~m}$ and that $\mathrm{r}_{\mathrm{e}}=$ $25000 \mathrm{~m}$ (taken from the area of the Lincs model, assuming it is circular). Values for $q, k$ and $h$ were also taken from Table 4 . For a variety of values of $r_{\mathrm{CO}_{2}}$ ranging from $0.07-0.15$ times $r_{e}$, this gives:

$$
P_{w}-\bar{P} \approx 2 \mathrm{MPa}
$$

If $P_{w}$ is taken as the fracture pressure, this means that the average pressure should be $2 \mathrm{MPa}$ less than expected in the Lincs model. A similar calculation for the Forth model gives a pressure difference of approximately $10 \mathrm{MPa}$

We can use the above calculations to obtain a correction in the storage efficiency to take account of the fact that the average pressure must be less than the fracture pressure. Then, substituting Equation (6b) into Equation (5), we obtain:

$$
\begin{aligned}
E & =c_{t} \times\left(P_{f}-P_{i}\right)-\frac{c_{t} q}{2 \pi k h}\left[\mu_{\mathrm{CO}_{2}} \ln \left(\frac{r_{\mathrm{CO}_{2}}}{r_{w}}\right)+\mu_{\text {brine }} \ln \left(\frac{0.47 r_{e}}{r_{\mathrm{CO}_{2}}}\right)\right] \\
& =E_{f}-\frac{c_{t} q}{2 \pi k h}\left[\mu_{\mathrm{CO}_{2}} \ln \left(\frac{r_{\mathrm{CO}_{2}}}{r_{w}}\right)+\mu_{\text {brine }} \ln \left(\frac{0.47 r_{e}}{r_{\mathrm{CO}_{2}}}\right)\right]
\end{aligned}
$$

where $E_{f}$ is the storage capacity which would be estimated from the fracture pressure gradient and the and initial pressure, assuming pressure equilibrium. The actual storage efficiency is less, and may be approximated by the second term on the right of Equation (7), and depends on the flow rate and the pressure diffusivity. Obviously, this means that the higher the injection rate, the larger the error in calculating the storage efficiency using the compressibility method. For $c_{t}=9 \times 10^{-4} \mathrm{MPa}^{-1}$ (from Table 4 ), this gives an error in $\mathrm{E}$ of $0.16 \%$ and $0.92 \%$ for the Lincs and Forth models, respectively, assuming that $r_{\mathrm{CO}_{2}}=0.1 r_{e}$. Note, though, that these calculations assume that all the $\mathrm{CO}_{2}$ is injected through a single well, whereas in the simulations, 15 wells were used. The errors are likely to be smaller, depending on the spacing of the wells.

The maximum allowable pressure may not be determined by the fracture pressure. For example, the pressure should be lower than the capillary entry pressure $\mathrm{P}_{c e}$ for $\mathrm{CO}_{2}$ in the caprock. In this study, it was assumed in the compressibility and semi-closed method that the capillary entry pressure for the cap rock was not exceeded. In the simulations, the entry pressures used for the caprocks were 2.1 MPa for the Lincs model and 1.6 MPa for the Forth model (Table 3), which is lower than the difference between the fracture pressure and the initial pressure. However, the results of the simulations showed that the pressure did not build up sufficiently under the caprock for $\mathrm{CO}_{2}$ to enter.

In the calculations below, the maximum allowable average pressure increase is assumed to be 1.4 times of the hydrostatic pressure in the compressibility method (closed method) and the semi-closed method, as used by Zhou et al. and Brook et al. (Brook et al., 2003; Zhou et al., 2008). This value was chosen for simplicity and because it was the minimum of the values from Obdam (2000) at the appropriate depth range. In the numerical simulations, the maximum injection pressure for each $\mathrm{CO}_{2}$ injector was also set to be 1.4 times of the initial pore pressure. 


\section{Hypothetical Storage Sites}

In the CASSEM project (Smith et al., 2011), two hypothetical near-shore storage sites in the UK were assessed using both static (compressibility) and dynamic (semi-closed method and numerical simulation) methods. One site was in Lincolnshire (referred to as "Lincs") and the other in the Firth of Forth (referred to as "Forth"). A description of these sites is given below, followed by a comparison of the storage efficiency results for each site. The models used for numerical simulation were constructed using available geological data, which was sparse compared with data available for a hydrocarbon reservoir, but adequate for the present study.

\section{Lincs Model}

The target aquifer is in the Triassic Sherwood Sandstone Group (SSG). This formation, which occurs on the east of England, dips at a low angle towards the east, and has a relatively uniform thickness of $300 \mathrm{~m}$. The injection point lies at a depth of $1200 \mathrm{~m}$. The SSG consists of fluvial sandstones of high permeability with isolated thin, discontinuous mudstone units. The lateral extent of these mudstone units is not known, but thought to be approximately $100 \mathrm{~m}$, and they are typically about $1 \mathrm{~m}$ thick (Ford and Monaghan, 2009). The caprock is the Mercia Mudstone Group (MMG) and the underlying formation is the Roxby Formation (mudstone). The average porosity of the SSG in this region is approximately 0.2 and the average permeability is $500 \mathrm{mD}$. Onshore 3D and 2D seismic data were interpreted, and borehole and well log data were used to create a 3D geological model (Ford et al., 2008). The model is shown in Figure 1 (left), which had an areal extent of $43 \mathrm{~km}$ by $30.15 \mathrm{~km}$, was modelled using $96 \mathrm{x} 67$ grid cells of $450 \mathrm{~m}$ by $450 \mathrm{~m}$. The model was $600 \mathrm{~m}$ in the vertical direction, with 15 cells of varying thicknesses, ranging from $4.65 \mathrm{~m}$ at the top of the aquifer to resolve the $\mathrm{CO}_{2}$ plume to $130 \mathrm{~m}$ at the bottom of the model. The distributions of petrophysical properties in the model were generated stochastically using Sequential Gaussian Simulation method in the PETREL ${ }^{\mathrm{TM}}$ package, and the permeability distribution was created by correlating log (permeability) with porosity. Table 1 gives the input parameters for the porosity and permeability in the stochastic geological model. The semi-variogram for the Sherwood Sandstone was estimated from borehole data to have a range of $0.1 \mathrm{~m}$ in the vertical direction. In the absence of sufficient data, the range in the horizontal direction was estimated to be $2000 \mathrm{~m}$, and was isotropic. Note that, since the size of the cells was large compared with the expected size of the mudstone layers, the mudstones were not modelled specifically. Instead their effect was taken into account in the ratio of vertical to horizontal permeability: $\mathrm{kv} / \mathrm{kh}=0.1$. The net-to-gross ratio $(\mathrm{N} / \mathrm{G})$ was estimated from Ford and Monaghan (2009) to be 0.9 , and was set constant throughout the model.

Some NW-SE trending faults were present in the Lincs model, but did not form extensive barriers to flow. The transmissibility of the faults is unknown, so in the simulation models, the transmissibility was varied between 0 and 1 across the faults.

The rock compressibility was set to $5 \times 10^{-4} \mathrm{MPa}^{-1}$ in the aquifer, caprock and underburden, this value being estimated from geomechanical measurements of cores from a nearby borehole.

The geothermal and the brine salinity data for this study were taken from Downing et al (1985). The temperature gradient was set to $35^{\circ} \mathrm{C} / \mathrm{km}$, based on the measured temperatures in the Cleethorpes Borehole. The salinity gradient was based on the analysis of pore water samples, in which the concentration of $\mathrm{Na}$ varied from $18,800 \mathrm{mg} / \mathrm{L}$ at $1204 \mathrm{~m}$ to $72,200 \mathrm{mg} / \mathrm{L} \mathrm{at} 1868 \mathrm{~m}$.

Table 1 Statistical input parameters for the Lincs Model.

\begin{tabular}{|l|c|c|c|c|}
\hline \multirow{2}{*}{ Formation } & \multicolumn{2}{|c|}{ Porosity (\%) } & \multicolumn{2}{c|}{ Permeability } \\
\cline { 2 - 5 } & average & std. dev & $\begin{array}{c}\text { geom ave } \\
(\mathrm{mD})\end{array}$ & $\begin{array}{c}\text { std. dev in } \\
\ln (\mathrm{k})\end{array}$ \\
\hline Mercia Mudstone & 10 & 3 & 0.005 & 0.1 \\
\hline Sherwood Sandstone & 21.5 & 2 & 500 & 0.5 \\
\hline Roxby Formation & 3 & 1 & 0.005 & 0.1 \\
\hline
\end{tabular}

\section{Forth Model}

The other target aquifer is in the Kinnesswood and Knox Pulpit Formations (K\&K) in the east of Scotland. The Knox Pulpit Formation is mainly aeolian, and is a laminated sandstone. It also contains isolated mudstone units. The Kinnesswood, which lies above the Knox Pulpit Formation is predominantly fluvial in origin (Ford and Monaghan, 2009). The caprock is the Ballagan Formation, and the underlying formation is the Glenvale.. However, The main aquifer/seal levels are at interpreted depths of 2000 to $2300 \mathrm{~m}$ on an anticline structure, where the injector is located in Figure 1 (right). Because the target area is between two syncline structures, the deepest part of the base of the storage formation is below $4000 \mathrm{~m}$. In the original model for the Forth Site there were a number of faults. However, the seismic data was re-processed and re-interpreted (McInroy and Hulbert, 2010) and the new model, which was used in this study had no faults. The lateral extent of the model was $17.6 \mathrm{~km}$ by $15.8 \mathrm{~km}$ and it was divided up into $88 \times 79$ grid cells of side $200 \mathrm{~m}$ in the horizontal. The thickness of the model was approximately $300 \mathrm{~m}$, and the cell thickness varied from $500 \mathrm{~m}$ in the underburden to $2.4 \mathrm{~m}$ at the top of the aquifer.

The geological interpretation and modelling are described in Monaghan et al. (2008), and the porosity and permeability data input into the stochastic geological model are summarised in Table 2. Again the petrophysical properties were generated stochastically using PETREL ${ }^{\mathrm{TM}}$. The structure in this region is much more complex than in Lincs region, with lower porosity and permeability. 
The average porosity of the aquifer is about 0.135 and the average permeability is $60 \mathrm{mD}$. The porosity was modelled first using SGS, with a vertical range of $0.1 \mathrm{~m}$ and a horizontal range of $2000 \mathrm{~m}$. The permeability distribution was generated using "collocated co-kriging" (Journel and Huijbregts, 1997), with a correlation coefficient of 0.6 (obtained from log(k)- $\phi$ cross-plots of core data). A constant N/G of 0.8 was applied, estimated by Ford and Monaghan ( 2009). The kv/kh ratio was again taken as 0.1 to account for the discontinuous low permeability units (isolated mudstones). As in the Lincs model, the rock compressibilities for the aquifer and caprock were set to $5 \times 10^{-4} \mathrm{MPa}^{-1}$.

In both models, the detailed regions of the models were extended laterally using numerical aquifers in order to cover the whole geological structure, while concentrating on the region of $\mathrm{CO}_{2}$ migration.

Table 2 Statistical input parameters for the Forth Model.

\begin{tabular}{|l|c|c|c|c|}
\hline \multirow{2}{*}{ Formation } & \multicolumn{2}{|c|}{ Porosity (\%) } & \multicolumn{2}{c|}{ Permeability } \\
\cline { 2 - 5 } & average & std. dev & $\begin{array}{c}\text { geom ave } \\
(\mathrm{mD})\end{array}$ & $\begin{array}{c}\text { std. dev in } \\
\ln (\mathrm{k})\end{array}$ \\
\hline Ballagan & 6.8 & 3.7 & 0.0061 & 0.1 \\
\hline Kinnesswood & 11.8 & 5.4 & 0.96 & 3.0 \\
\hline Knox Pulpit & 15.1 & 4.0 & 7.59 & 1.5 \\
\hline Glenvale & 15.0 & 4.0 & 1 & 1.5 \\
\hline
\end{tabular}

Figure 1 The 3D models for Lincs (left) and Forth (right) showing the porosity distributions. Part of the caprock has been removed to show the permeability distribution of the aquifer. Note that, although the diagrams show a single well, multiple wells were used in the simulations .

\section{Relative Permeability and Capillary Pressure}

There is a scarcity of measurements of $\mathrm{CO}_{2}$-brine relative permeabilities. Many studies make use of data from Bennion and Bachu (Bennion and Bachu, 2008). However, in this study, relative permeabilities were measured on a single core sample from the Cleethorpes borehole, near the Lincs site (Smith et al., 2012). The resulting relative permeabilities are shown in Figure 2. These curves were used for both models.

No capillary pressure measurements were available, so curves were generated using the Brooks-Corey formula (Brooks and Corey, 1964):

$$
P_{c}=P_{c e} S_{n}^{-1 / \lambda}
$$


where $P_{c e}$ is the capillary entry pressure, $S_{n}$ is normalised saturation, and $\lambda$ is a parameter related to the sorting of the grains, which was taken as 2 in this project. The value for the capillary entry pressure was set for each rock type (sandstone or mudstone) and depended on $\sqrt{\phi / k}$ (Table 3 ). The capillary pressure curves for the two aquifer formations are shown in Figure $2 b$.

Table 3 The Capillary entry pressures.

\begin{tabular}{|l|c|c|c|}
\hline Formation & Porosity $\phi$ & Permeability k & $\mathrm{P}_{\text {ce }}(\mathrm{MPa})$ \\
\hline Mercia Mudstone & 0.100 & 0.005 & 2.11 \\
\hline Sherwood Sandstone & 0.225 & 500.000 & 0.01 \\
\hline Ballagan & 0.067 & 0.0061 & 1.57 \\
\hline Knox Pulpit & 0.150 & 7.59 & 0.07 \\
\hline
\end{tabular}

a)

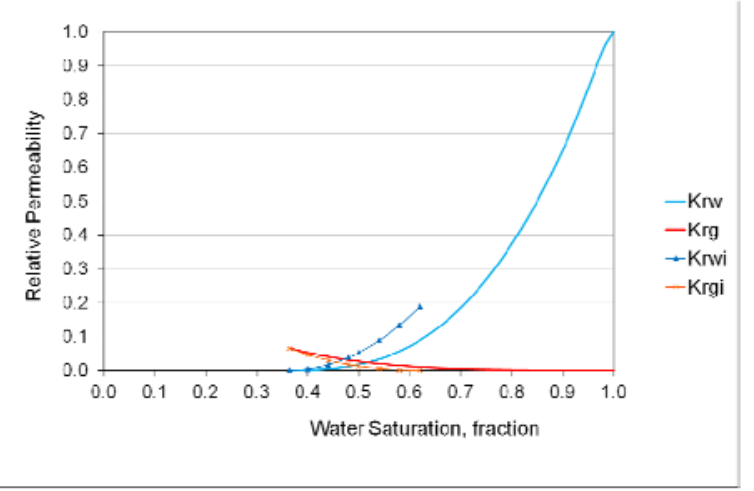

b)

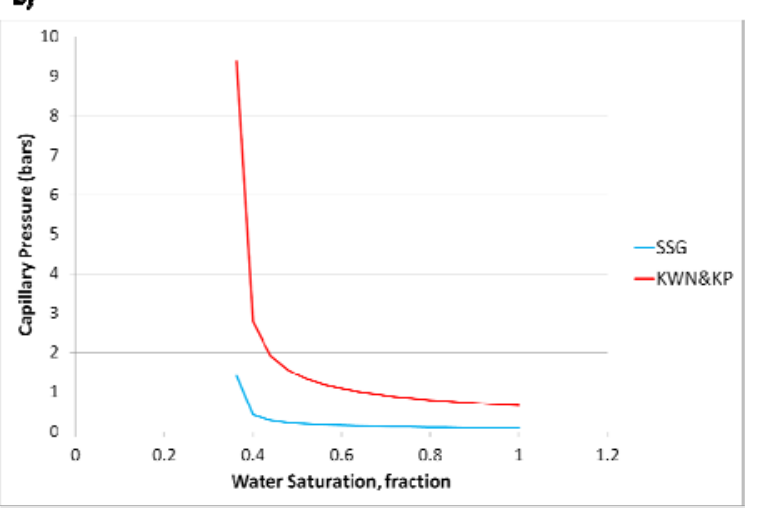

Figure 2 Relative permeabilities and capillary pressures. (The curves labeled "Krwi" and "Krgi" are for imbibition. The gas imbibition curve is very close to the drainage curve.)

\section{Capacity estimation and comparison with simulation results}

At each site, the simple methods were used to estimate $\mathrm{CO}_{2}$ storage assuming a closed system (Equation 2), and then a semi-closed system (Equation 3). We assumed in all cases that the total injection rate was $15 \mathrm{Mt} / \mathrm{yr}$, which is equivalent to the amount of $\mathrm{CO}_{2}$ emitted by a large power station. In addition, the storage efficiency was estimated using numerical simulation. Fifteen wells were used with a target injection rate $1 \mathrm{Mt} / \mathrm{yr}$ for each well. The wells were constrained by pressure build-up, and the rate was reduced when the maximum pressure was reached.

Two sets of capacity estimates were made for the semi-closed and the numerical simulation methods. Firstly, the storage effeciency was calculated after 15years, which was the assumed length of the injection period. Zhou et al. (2008) refer to the efficiency as the actual storage efficiency in this case. Secondly, for the numerical simulation, the maximum storage efficiency was calculated by allowing injection to continue until the total field injection rate reduced to a quarter of its initial value due to the wellbore pressure constraint. (See discussion in next section.) For the analytical methods, the maximum storage efficiency was calculated using maximum pressure.

The storage efficiency is affected, to a certain degree, by the number of wells, their spacing and their injectivity (which depends on the local permeability distribution). In order to compare the storage capacity calculated by numerical simulation with the value from the static estimation and the semi-closed method, the average field pressure was also an output in the numerical simulation.

\section{Results for Lincs Model}

From the simulation model, the total pore volume of the Sherwood Sandstone formation is $1.32 \mathrm{E} 11 \mathrm{~m}^{3}$ and the total pore volume of the seal formations is 7.76E10 $\mathrm{m}^{3}$ (overlying MMG Fm and underlying Roxby Fm for Lincs Model). The porosity of the seal formation was assumed to be 0.1 (average of MMG and Roxby formations). The thickness of the aquifer formation and seal formation were based on a borehole data. The input parameters for the estimation are listed in Table 4. 
The results for the storage efficiencies are shown in Table 5. The closed method gave a storage efficiency of only $0.34 \%$, allowing injection of $\mathrm{CO}_{2}$ for 20.3 years. In the semi-closed method, the maximum pressure (13.2 $\left.\mathrm{MPa}\right)$ was reached at 40 years, when the storage efficiency was $0.41 \%$. In the numerical simulation, the total injection rate was reduced to $25 \%$ of the target rate after 50 years, and gave a storage efficiency of $0.61 \%$. The mass of $\mathrm{CO}_{2}$ injected in the numerical simulation was approximately $538 \mathrm{Mt}$. Table 5 also shows the fractions $F_{f}, F_{s}$, and $F_{l}$ which represent different contributions to the storage of $\mathrm{CO}_{2}\left(\mathrm{Zhou}\right.$ et al, 2008). $F_{f}$ is the proportion of storage due to compression of the brine and pore space in the aquifer, $F_{s}$ is the proportion of storage due to the compression of the brine and pore space in the seal, and $F_{l}$ is the proportion due to brine moving into overlying or underlying formations. The main point to note is that the numerical simulation has much less brine displaced into the seals, and also no brine has leaked through the seals (because we defined closed boundaries).

Figure 3 illustrates the build-up of the pressure in one of the wells (WBHP), the average pressure (FPR) and the field injection rate (FGIR) as a function of time. The average pressure is the value output by the simulator and is the average pressure for the whole model. The initial average pressure is $9.38 \mathrm{MPa}$, whereas the initial WBHP for injector well-12 at a datum depth of $1261 \mathrm{~m}$ is $13.1 \mathrm{MPa}$. The wellbore pressure increases rapidly in the first few years. This is caused partly by gridding effects: when $\mathrm{CO}_{2}$ enters a grid cell, it spreads throughout the cell, therefore producing low saturation and giving rise to low $\mathrm{CO}_{2}$ mobility. Tests with grids of different resolution show that as the grid is refined, the initial rise in pressure is reduced and occurs at earlier times. However, part of the initial pressure rise is genuine and is caused by the decrease in mobility at intermediate saturation values. The wells reached the maximum bottom hole pressure (BHP) at different times. When each well reached the BHP limit, its control was switched from rate to BHP. It can be seen from the total injection rate in Figure 3 that most of wells reached their maximum pressure after 20 years, when the average field pressure had increased by about $20 \%$ of its initial value. At this stage, the total injection rate was only $1 / 4$ of the initial rate, and the pressure levelled off. In a real $\mathrm{CO}_{2}$ storage project, there is a minimum practical limit to the injection rate. We decided to calculate the storage efficiency at this stage - i.e. when the injection rate had fallen to $1 / 4$ of the initial rate.

Table 4 Input parameters of simple estimation of storage capacity for Lincs and Forth

\begin{tabular}{|c|c|c|c|c|}
\hline Parameters & Symbol & Unit & Lincs & Forth \\
\hline Area & $A$ & $\mathrm{~m}^{2}$ & $2.00 \mathrm{E}+09$ & $2.84 \mathrm{E}+09$ \\
\hline Thickness & $h$ & $\mathrm{~m}$ & 330 & 300 \\
\hline Aquifer porosity & $\phi$ & & 0.20 & 0.135 \\
\hline Aquifer pore volume & $V_{f p}$ & $\mathrm{~m}^{3}$ & $1.32 \mathrm{E}+11$ & $1.15 \mathrm{E}+11$ \\
\hline \multirow[t]{2}{*}{ Aquifer permeability } & $k$ & $\mathrm{~m}^{2}$ & $5.0 \mathrm{E}-13$ & $6.8 \mathrm{E}-14$ \\
\hline & & $\mathrm{mD}$ & 500 & 68 \\
\hline \multirow[t]{2}{*}{ Seal permeability } & $k_{s}$ & $\mathrm{~m}^{2}$ & $5.0 \mathrm{E}-18$ & $4.8 \mathrm{E}-18$ \\
\hline & & $\mathrm{mD}$ & 0.005 & 0.0048 \\
\hline Seal thickness ${ }^{1}$ & $h_{s}$ & $\mathrm{~m}$ & 194 & 97 \\
\hline Seal porosity & $\phi_{s}$ & & 0.1 & 0.1 \\
\hline Total seal pore volume ${ }^{2}$ & $V_{s p}$ & $\mathrm{~m}^{3}$ & $7.76 \mathrm{E}+10$ & $5.50 \mathrm{E}+10$ \\
\hline Water compressibility & $c_{w}$ & $1 / \mathrm{MPa}$ & $4.00 \mathrm{E}-4$ & $4.00 \mathrm{E}-4$ \\
\hline Aquifer pore compressibility & $c_{p}$ & $1 / \mathrm{MPa}$ & $5.00 \mathrm{E}-4$ & $5.00 \mathrm{E}-4$ \\
\hline Seal pore compressibility & $c_{p s}$ & $1 / \mathrm{MPa}$ & $5.00 \mathrm{E}-4$ & $5.00 \mathrm{E}-4$ \\
\hline Water viscosity & $\mu_{w}$ & Pa-s & 0.001 & 0.001 \\
\hline Initial pressure & $P_{0}$ & $\mathrm{MPa}$ & 9.4 & 29 \\
\hline Maximum pressure & $P_{\max }$ & $\mathrm{MPa}$ & 13.2 & 40.6 \\
\hline $\mathrm{CO}_{2}$ density at surface & $\rho_{c o 2}$ & $\mathrm{~kg} / \mathrm{m}^{3}$ & 1.90 & 1.90 \\
\hline $\mathrm{CO}_{2}$ density at initial pressure & $\rho_{\mathrm{CO} 2(\mathrm{PO})}$ & $\mathrm{kg} / \mathrm{m}^{3}$ & 630 & 840 \\
\hline $\mathrm{CO}_{2}$ density at maximum pressure & $\rho_{c o 2(\operatorname{Pmax})}$ & $\mathrm{kg} / \mathrm{m}^{3}$ & 710 & 920 \\
\hline
\end{tabular}




\begin{tabular}{|l|l|l|l|r|} 
Total field Injection rate $^{3}$ & $q$ & $\mathrm{sm}^{3} / \mathrm{s}$ & $2.5 \mathrm{E}+02$ & $2.5 \mathrm{E}+02$ \\
\hline
\end{tabular}

${ }^{1}$ This is the thickness of a seal above or below the aquifer. The two seals are assumed to be of equal thickness.

${ }^{2}$ This is the total pore volume of the seal - above and below the aquifer.

${ }^{3}$ Equivalent to $14.6 \mathrm{Mt} /$ year, at density of $\mathrm{CO}_{2} \rho \mathrm{CO}_{2}=700 \mathrm{~kg} / \mathrm{m}^{3}$.

Table 5 Comparison of the calculation of storage efficiency and storage capacity with the numerical simulation results. $F$ is the fraction of displaced brine. The subscripts $f, s$ and $I$ represent the storage formation, the seal and the amount leaked out of the model.

\begin{tabular}{|c|c|c|c|c|c|c|c|c|c|c|}
\hline \multirow{3}{*}{$\begin{array}{l}\text { Storage } \\
\text { efficiency }\end{array}$} & \multicolumn{5}{|c|}{$\overline{\text { Lincs }}$} & \multicolumn{5}{|c|}{ Forth } \\
\hline & \multirow{2}{*}{$\begin{array}{c}\begin{array}{c}\text { Closed } \\
\text { system }\end{array} \\
t_{\max }\end{array}$} & \multicolumn{2}{|c|}{$\begin{array}{l}\text { semi-closed } \\
\text { system }\end{array}$} & \multicolumn{2}{|c|}{$\begin{array}{l}\text { Numerical } \\
\text { simulation }\end{array}$} & \multirow{2}{*}{$\begin{array}{c}\text { Closed } \\
\text { system }\end{array}$} & \multicolumn{2}{|c|}{$\begin{array}{l}\text { semi-closed } \\
\text { system }\end{array}$} & \multicolumn{2}{|c|}{ Numerical simulation } \\
\hline & & $t_{15 y r}$ & $t_{\max }$ & $t_{15 y r}$ & $t_{\max }$ & & $t_{15 y r}$ & $t_{\max }$ & $t_{15 y r}$ & $t_{\max }$ \\
\hline$t_{\max }($ year $)$ & 20.3 & & 40.0 & & 50 & 71.3 & & $(150)^{1}$ & & 150 \\
\hline$E(\%)$ & 0.34 & 0.16 & 0.41 & 0.26 & 0.61 & 1.04 & 0.15 & $(1.53)^{1}$ & 0.17 & 1.05 \\
\hline$F_{f}$ & 1.00 & 0.66 & 0.51 & 0.91 & 0.89 & 1.00 & 0.50 & 0.08 & 0.77 & 0.78 \\
\hline$F_{S}$ & - & 0.19 & 0.15 & 0.09 & 0.11 & - & 0.12 & 0.02 & 0.23 & 0.22 \\
\hline$F_{l}$ & - & 0.15 & 0.34 & - & - & - & 0.38 & 0.90 & - & - \\
\hline
\end{tabular}

${ }^{1}$ The maximum pressure was not reached in this case, so the time for the numerical simulation was taken. 


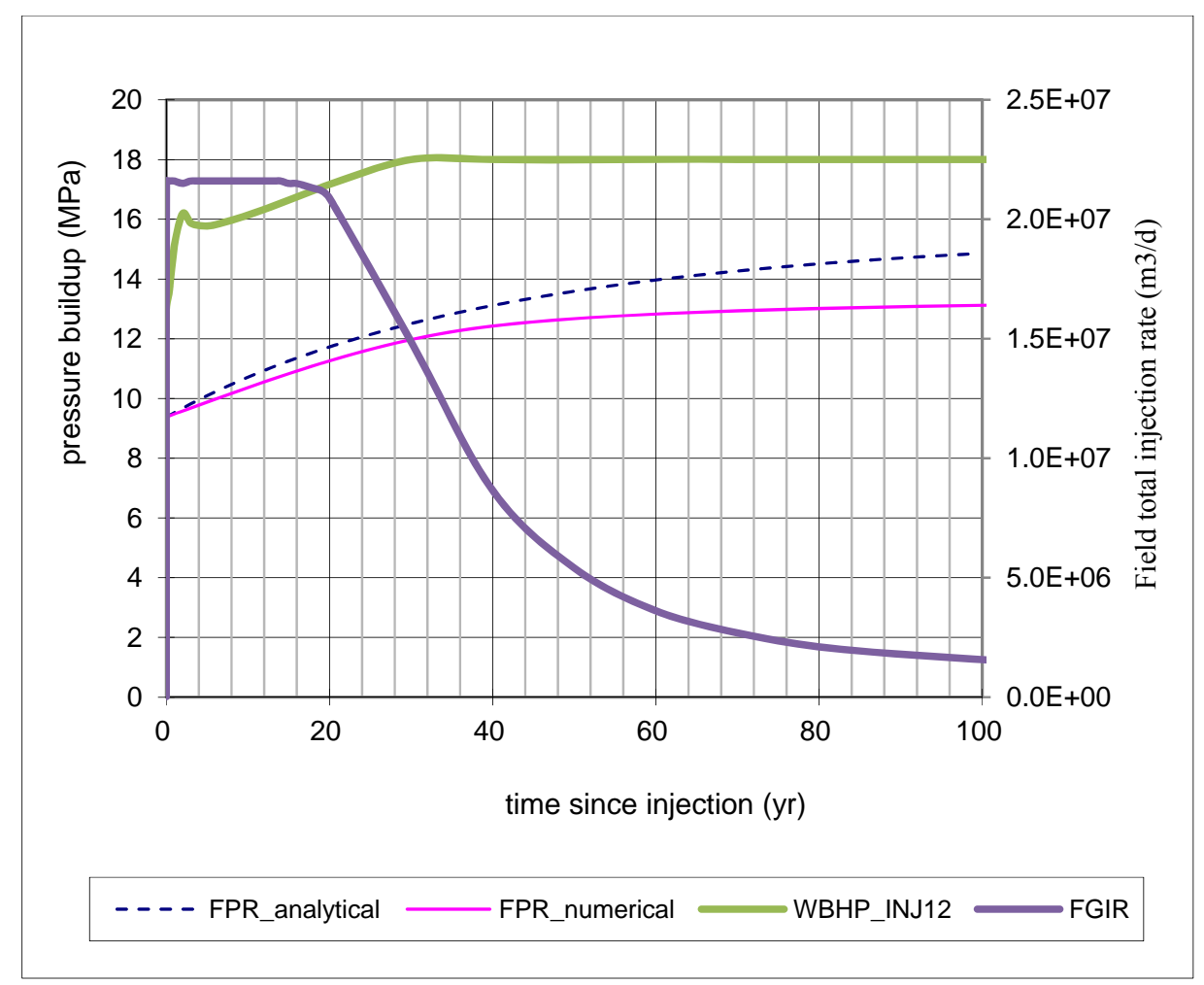

Figure 3 Comparison of the field average pressure (FPR) vs. time from numerical simulation (dotted line) with the calculated pressure from the semi-closed method (solid line). The graph also shows the well bottom hole pressure (WBHP) for one injector (Well 12) and total $\mathrm{CO}_{2}$ injection rate as a function of time for Lincs, from the numerical simulation.

As mentioned above, the advantage of performing a numerical simulation is that the amount of $\mathrm{CO}_{2}$ which dissolves or is trapped at the pore scale (residual trapping) may be calculated. In Figure 4, we show the proportions of $\mathrm{CO}_{2}$ in the mobile gas phase, the immobile gas phase and dissolved in brine. In this simulation, $\mathrm{CO}_{2}$ was injected 15 years. The well was shut in and then the simulation was continued for a further 5000 years. After injection ceases, the mobile $\mathrm{CO}_{2}$ gradually dissolves in the brine. Also, some of the immobile (capillary trapped) $\mathrm{CO}_{2}$ dissolves. After 5000 years, approximately $35 \%$ of the $\mathrm{CO}_{2}$ has dissolved in brine, nearly $100 \%$ is immobile.

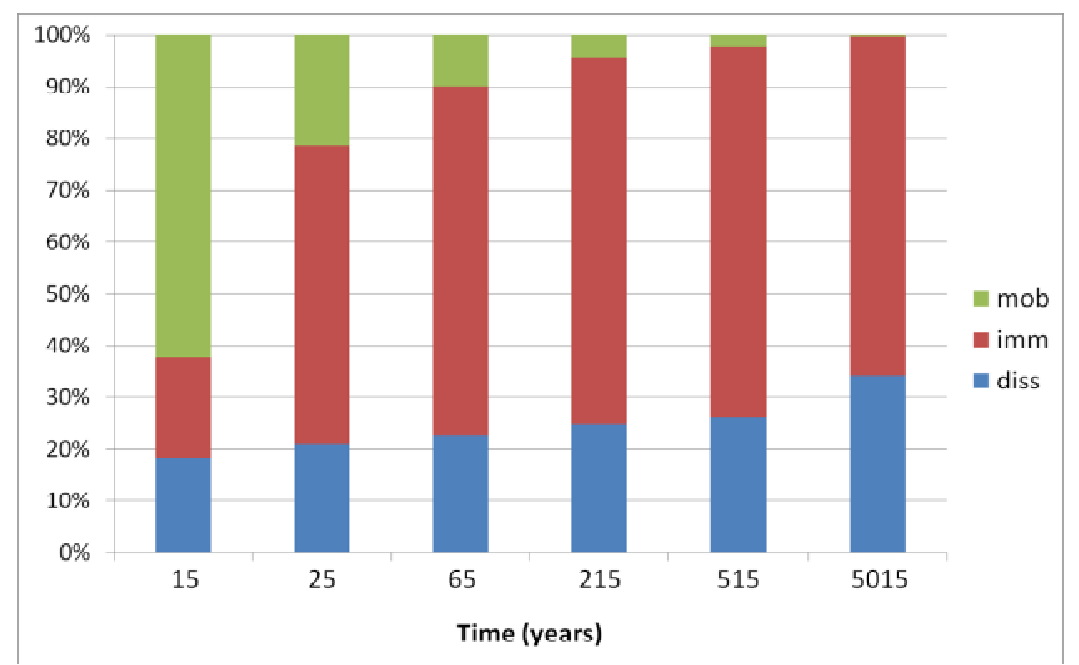

Figure 4 Fraction of injected $\mathrm{CO}_{2}$ in different phases vs. time for Lincs Model, which shows the residual trapping. 


\section{Results for Forth Model}

Estimates of the storage efficiency were calculated for the Forth Model in a similar manner. The volumes of the aquifer and seal used in the estimates were again taken from simulation model (Table 1). In this case the closed method predicts a storage efficiency of $1.16 \%$. Figure 5 shows the build up of pressure as $\mathrm{CO}_{2}$ is injected into the Forth model. Because the injection is near the crest of an anticline and much of the model is at a greater depth, the pressure at the well is lower than the average reservoir pressure. A comparison of the build up of pressure in the numerical and the semi-closed model is given in Figure 5. It can be seen that the average field pressure increases more quickly in the numerical simulation than in the analyltical model. As with the Lincs model, the pressure reaches an asymptote in the simple estimation. However, in this case the asymptote is lower than the maximum pressure of $40 \mathrm{MPa}$. In fact the pressure only increased by $1.8 \mathrm{MPa}$, compared to $5.5 \mathrm{MPa}$ in the Lincs model. The reason for this is that more brine could leak through the seal in the semi-closed method in the Forth model, due to the fact that the area was larger and the seal was thinner (see Equation 3). Additionally, because the Forth site is deeper, the injection of a certain volume at the surface is reduced to a smaller volume in the aquifer. The total field injection rate reaches $25 \%$ of its initial value after 150 years in the numerical simulation. For comparision, we have therefore calculated the storage efficiency at this time using the semi-closed method. This gave a storage efficiency of $1.5 \%$, while the numerical simulation gave a value of $1 \%$. Note, though, that if we perform the semi-closed calculations for longer periods of time, the storage efficiency will keep increasing because the maximum pressure is never reached.

All of the storage efficiency estimates calculated for the Forth are higher than the values obtained for the Lincs model by a factor of 2 - 3. The reason is that the Forth is deeper so the initial pressure is higher. Since we allow the pressure to increase by a factor of 1.4 in both models, the allowable pressure increase and the density of $\mathrm{CO}_{2}$ are greater in Forth, allowing more $\mathrm{CO}_{2}$ to be stored. (The penalty is that more energy would be required to provide the additional compression for this greater depth.) The mass of $\mathrm{CO}_{2}$ stored in the numerical simulation was approximately $1017 \mathrm{Mt}$.

No initial maximum in the WBHP was found in Forth model. Due to the low permeability, a number of wells switched immediately to pressure control, and the total injection rate was reduced significantly at the beginning of the injection as shown in Figure 5.

Figure 6 shows the change of the fraction of mobile and immobile $\mathrm{CO}_{2}$ and the dissolved $\mathrm{CO}_{2}$ with time. Again, $\mathrm{CO}_{2}$ was injected for 15 years, the well was shut in, and then the simulation was continued for another 5000 years. Both models (Lincs and Forth) have negligible free $\mathrm{CO}_{2}$ at the end of the simulation (5000 years after shut-in). At the end of injection, there is slightly more free $\mathrm{CO}_{2}$ in the Forth model than the Lincs one. The solubility of $\mathrm{CO}_{2}$ is much lower than in Lincs because the salinity of brine is higher. Residual trapping in the Forth model compensates the loss of solubility trapping.

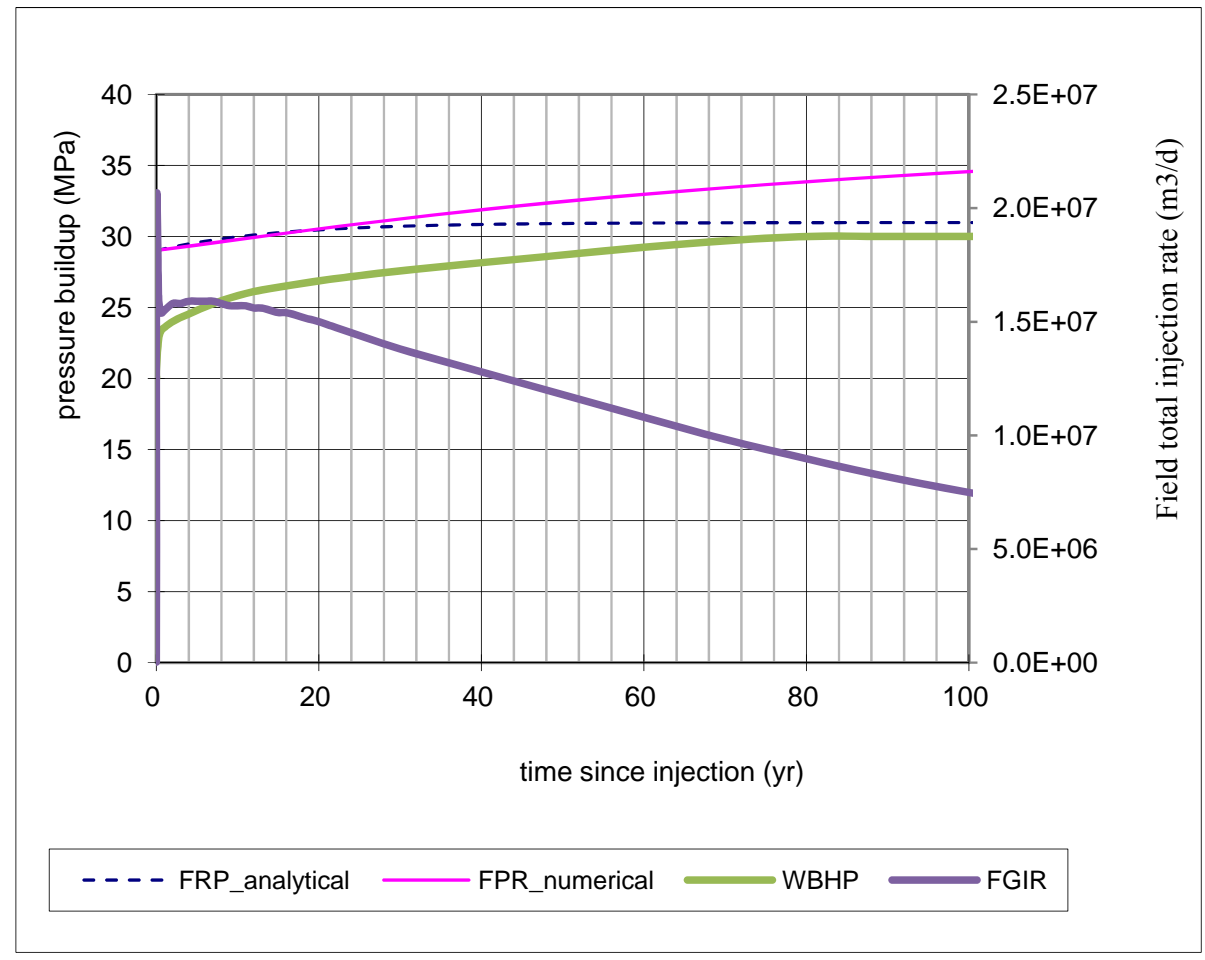

Figure 5 Comparing the field average pressure (FPR) change with time from numerical simulation (dot line) with calculated from semiclosed method (solid line); and showing the well bottom hole pressure (WBHP), total field CO2 injection rate as a function of time for Forth, from the numerical simulation. 


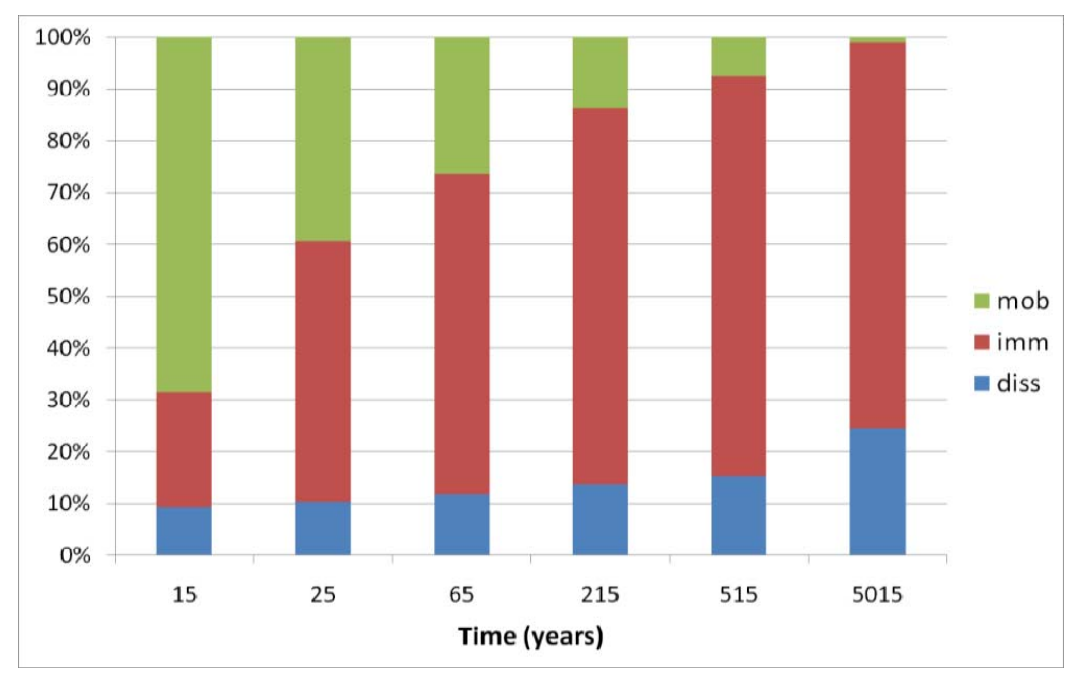

Figure 6 Fraction of injected $\mathrm{CO}_{2}$ in different phases vs. time for Forth Model, which shows the residual trapping.

Further Results from the Numerical Simulations

So far, we have only considered the results of the numerical simulations as a whole, so that we can compare them with the results of the simple estimates. An important aspect of numerical simulation is to monitor the migration of free $\mathrm{CO}_{2}$. Figure 7 shows the distribution of $\mathrm{CO}_{2}$ in the aquifers at both sites 1000 years after shut in. The results show a heterogeneous distribution, due to variations in the topography of the top surface. Obviously, if $\mathrm{CO}_{2}$ can migrate far from an injector, there is a possibility of it reaching the limit of the seal, and leaking into shallower formations. In the Forth model, if we consider a safe storage region as the volume under the central anticline (where the $\mathrm{CO}_{2}$ concentration is highest - Figure 6), then the storage efficiency will be considerably reduced. Volumetric calculations for the anticline, assuming a storage efficiency of $E=2 \%$, showed that only $237 \mathrm{Mt}$ may be stored in this region, compared to $1017 \mathrm{Mt}$ if the whole aquifer is considered.

Building a simulation model requires a significant amount of input data. Our models were constructed using seismic data and some borehole data. However, we did not have access to as much data as might be the case for a hydrocarbon reservoir, and there is hence much uncertainty in some of the properties of the model. Also, in the absence of measured relative permeability data at this stage of the project, the relative permeability curves tested from Lincs site were used for Forth site, rather than measured data specific to that site. Despite this, the results of the simulations indicate how the $\mathrm{CO}_{2}$ may migrate, which is useful to know from the point of view of monitoring. Also the models will help to locate the optimal positions for additional injection wells in further studies. 


\section{Summary and Conclusions}

We investigated the $\mathrm{CO}_{2}$ storage efficiency in two contrasting hypothetical storage sites, using thee methods: the analytical compressibility method, the semi-analytical semi-closed method (Zhou et al., 2008), and numerical reservoir simulation. The first site (Lincs) had a simple structure with tilted layers and a relatively high average permeability and porosity. On the other hand, the Forth had a complex structure, including an anticline and two deep synclines, and had lower porosity and permeability. The Forth model was deeper than the Lincs one $(2000 \mathrm{~m}$ compared to $1000 \mathrm{~m})$. The heterogeneous structure in this model also affected the migration of $\mathrm{CO}_{2}$.

At both sites, the compressibility method gave lower storage efficiency values than the other two methods. This is because the compressibility method assumes a closed system. At the Lincs site, the results from the semi-closed method and numerical simulation were in reasonable agreement, giving $E=0.4-0.6 \%$. However, this is coincidental. In the semi-closed method, 34\% of the $\mathrm{CO}_{2}$ storage was due to leakage of brine through the seal out of the system, but there was no dissolution. On the other hand, the numerical simulation was closed above and below the seals, but did include dissolution. The semi-closed method was not reliable for the Forth model, because the pressure reached an asymptote which was below the maximum limit. Numerical simulation and the compressibility method gave $E=1 \%$, which is higher than the Lincs model. This is because the Forth model is at a greater depth and therefore at a greater initial pressure. Since we specified the pressure limit as 1.4 times the initial pressure, this allowed a larger pressure increase.

Due to uncertainty in aquifer properties, simple methods like the closed and semi-closed methods are bound to be used for preliminary assessment of storage capacity. The value of the numerical results here is that they can be used to inform us on the appropriateness of the analytical methods. Firstly, the three methods tested gave broadly similar results (within a factor of 2 in each field). However, the processes occurring in the models were very different. In the numerical simulations, the injection rate was limited by the pressure build-up near the wells. The average pressure in the reservoir was not one of the limiting factors because, once the injection rate has been reduced the pressure increase leveled off. The numerical simulations were therefore terminated by a minimum rate (1/4 of the initial rate). One suggestion for the closed method was that a correction should be applied to the storage efficiency to take account of the pressure build-up at the wells. However, this was not applied in the end because, as the injection rate is reduced, the magnitude of the correction is reduced.

In addition to monitoring the pressure build up over the whole model and in the near well region, the numerical simulations are useful for predicting the amount of $\mathrm{CO}_{2}$ dissolved or trapped at the pore scale (residual trapping), and they also indicate how free $\mathrm{CO}_{2}$ may migrate in these aquifers, so that injectors and monitoring wells can be optimally placed to maximize the storage capacity and to minimize the risk of leakage.

The analytical methods used in the study are simple and few data are required. For an aquifer with simple geology, like the Lincs model in this study, it can be used at the site screening stage. More fluid and rock properties, such as relative permeability, capillary entry pressure, pressure and thermal gradients, and geological data on the formation and faults are required for numerical simulation. However, estimation with more consideration of safety and uncertainty quantificaton can be made using sensitivity studies. The capacity calculated may be based not only on pressure constraints, but also on $\mathrm{CO}_{2}$ migration constraints. The injection rate and period may be computted on the properties of the aquifer and cap rock, possible $\mathrm{CO}_{2}$ migration paths, the location of faults and existing wells in oilfield nearby.

Although there are no plans to actually inject $\mathrm{CO}_{2}$ into these sites, similar off-shore sites are likely to be used in the future. Also, similar sites may be used on-shore or off-shore in other parts of the world.

\section{Acknowledgements}

This research is part of the CASSEM project, facilitated by the Technology Strategy Board (TSB). We wish to acknowledge the support of the TSB and the EPSRC and the project industry partners: AMEC, Marathon, Schlumberger, Scottish Power, and Scottish and Southern Energy, and the academic partners: British Geological Survey, Heriot-Watt University, University of Edinburgh, and the University of Manchester. We should also like to thank Schlumberger for the use of the PETREL and ECLIPSE software packages.

We should alo like to thank the anonymous referees for their useful comments.

\section{Nomenclature}

$$
\begin{aligned}
& \begin{array}{ll}
A & =\text { the area of storage aquifer }\left(\mathrm{m}^{2}\right) \\
c_{p}, c_{w}, c_{p s} & =\text { pore compressibility, water compressibility, and seal formation pore compressibility respectively }(1 / \mathrm{Pa}) \\
c_{t}, C_{t s} & =\text { total compressibility of aquifer and seal formation, } c_{t}=c_{p}+c_{w} ; c_{t s}=c_{p s}+c_{w}
\end{array} \\
& \begin{aligned}
E & \text { storage coefficient }
\end{aligned} \\
& \begin{aligned}
F_{f}=\left(c_{p}+c_{w}\right) \Delta P_{\max }\left(V_{p o r e} / V_{C O 2}\right) \\
=\text { fraction of } \mathrm{CO}_{2} \text { storage due to compression of the brine and pore space in the aquifer }
\end{aligned} \\
& F_{s}=0.5\left(c_{p s}+c_{w}\right) \Delta P_{\max }\left(V_{s} / V_{C O 2}\right)
\end{aligned}
$$


$=$ fraction of $\mathrm{CO}_{2}$ storage due to compression of the brine and pore space in the seals

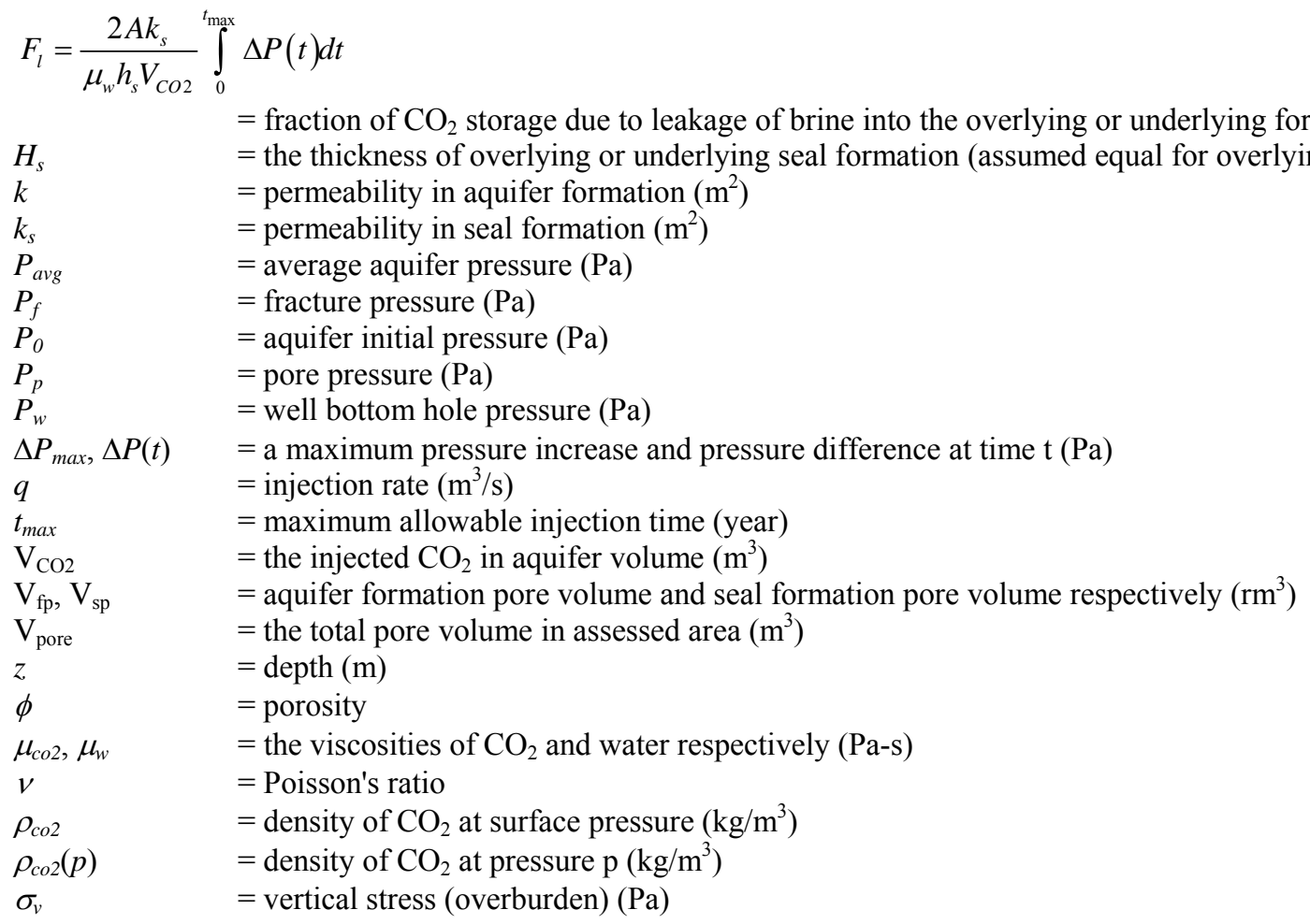

\section{References}

Bachu, S. et al., 2007a. Estimation of CO2 storage capacity in geological madia - CSLF Phase 2 report.

Bachu, S. et al., 2007b. CO2 storage capacity estimation: methodology and gaps. International Journal of Greenhouse gas control, 1: 430-443.

Bennion, B. and Bachu, S., 2008. Drainage and imbibition relative permeability relationships for supercritical CO2/brine and $\mathrm{H} 2 \mathrm{~S} /$ brine systems in intergranular sandstone, carbonate, shale, and anhydrite rooks. SPE Reservoir Evaluation \& Engineering, 11(3): 487-496.

Brook, M., Shaw, K., Vincent, C. and Holloway, S., 2003. Gestco case study 2a-1: Storage potential of the Bunter Sandstone in the UK sector of the southern North Sea and the adjacent onshore area of Eastern England. CR/03/154N, British Geological Survey.

Brooks, A.N. and Corey, A.T., 1964. Hydraulic Properties of Porous Media. Hydrol. Paper 3(1964): 27.

Burton, M., Kumar, N. and Bryant, S.L., 2008. CO2 injectivity into brine aquifers: why relative permeability matters as much as absolute permeability, GHGT-9

Chadwick, A. et al., 2006. Best practice for the storage of CO2 in saline aquifers - observatins and guidelines from the SACS and CO2STORE projects.

DOE, 2006. Carbon sequestration atlas of the United States and Canada: Appendix A - Methodology for development of carbon sequestration capacity estimates; report on the 2007 Carbon Sequestration Atlas of the United States and Canada (Atlas I). In: D.o.E. National energy Technology Laboratory (Editor).

DOE, 2008. Methodology for development of geologic storage estimates for carbon dioxide, report on the 2008 Carbon Sequestration Atlas of the United States and Canada (Atlas II). In: U.D.o.E.N.E.T. Laboratory (Editor). Capacity and fairways subgroup of the geologic working group of the DOE regional carbon sequestration partnerships.

Ford, J.R. and Monaghan, A.A., 2009. Lithological Heterogeneity of the Mercia Mudstone and Sherwood Sandstone Groups in the Yorkshire-Lincolnshire Region, and Knox pulpit Sandstone, Kinnesswood and Ballagan Formations in the Forth Region additional information for CASSEM work package one. CR/09/053, British Geological Survey, Edinburgh.

Ford, J.R., Monaghan, A.A., Milodowski, A.E. and Kirby, G.A., 2009. CASSEM work package one - Summary methodological report for 3D geological framework and rock sample mineralogy. CR/09/009, British Geological Survey, Edinburgh.

I think this is the wrong report to refer to here and it should be FORD, J.R., PHARAOH, T.C., HULBERT, A.G., VINCENT, C.J. \& COOPER, A.H. 2008. CASSEM Work Package One : British East Midlands and Lincolnshire geological modelling. British Geological Survey Report, CR/08/152

Frailey, S.M., 2009. Methods for estimating CO2 storage in saline reserviors. Energy Procedia, 1: 2769-2776. 
Frailey, S.M. and Finley, R.J., 2009. Classification of CO2 geologic storage: resource and capacity. Energy Procedia(1): 26232630.

Holloway, S., 1996. The underground disposal of carbon dioxide - report for JOULE II project, British Geological Survey.

Journel, A.G. and Huijbregts, C.J., 1997. Mining Geostatistics. Academic Press Limited, San Diego, California, U.S.A.

Kaldi, J.G. and Gibson-Poole, C.M., 2008. Storage capacity estimation, site selection and characterisation for CO2 storage projects; CO2CRC Report. RPT08-1001.

Mathias, S.A., Hardisty, P.E., Trudell, M.R. and Zimmenrman, R.W., 2009a. Appriximate solutions for pressure buildup during CO2 injection in brine aquifers. Transp Porous Med., 79: 265-284.

Mathias, S.A., Hardisty, P.E., Trudell, M.R. and Zimmenrman, R.W., 2009b. Screening and selection of sites for CO2 sequestration based on pressure buildup. International Journal of Greenhouse gas control, 3: 577-585.

Monaghan, A.A., McInroy, D.B., Browne, M.A.E. and Napier, B.R., 2008. CASSEM work package one - Forth geological modelling. CR/08/151, British Geological Survey, Edinburgh.

Nordbotten, J. and Celia, M., 2005. Injection and storage of CO2 in deep saline aquifers: analytic solution for CO2 plume evolution during injection. Transp. Porous Media 58: 339-360.

Nordbotten, J. and Celia, M., 2006. Similarity solutions for fluid injection into confined aquifers. J. Fluid Mech., 561: $307-327$.

Obdam, A., 2000. Auifer storage capacity of CO2, TNO- Built Environment \& Geosciences, Utrecht, The Netherlands.

SCCS, 2009. Opportunities for CO2 Storage Around Scotland. Scottish Carbon Capture and Storage.

Schlumberger, 2010. ECLIPSE Reference Manual. Schlumberger.Available at: Accessed: 2008.1

Smith, M., Campbell, D., Mackay, E. and Polson, D., 2011. CO2 Aquifer Storage Site Evaluation and Monitoring: Understanding the Challenges of CO2 Storage: Results of the CASSEM Project. Scottish Carbon Capture and Storage (SCCS).

Ukaegbu, C. et al., 2009. Simulation of CO2 storage in a heterogeneous aquifer. Proceedings of the Institution of Mechanical Engineers, Part A: Journal of Power and Energy, 223(3): 249-267.

van der Meer, L.G.H. and Egberts, P.J.P., 2008. A general mothod for calculating subsurface CO2 storage capacity, 2008 Offshore technoloty conference, Houston, Texas, USA.OTC 19309

van der Meer, L.G.H. and Yavuz, F., 2009. CO2 storage capacity calculations for the Dutch subsurface. Energy Procedia, 1: 26152622.

Zhou, Q., Birkholzer, J.T., Tsang, C.-F. and Rutqvist, J., 2008. A method for quick assessment of CO2 storage capacity in closed and semi-closed saline formations. International Journal of Greenhouse gas control(2): 626-639. 